\title{
An Efficient Separation of Pyrroloquinoline Quinone Using Chemical Complexation Extraction
}

\author{
XuePeng Yang, Panpan Li, Fangfang Wang, Jianbin Ye, Ke Ma*, Duobin Mao \\ School of food and biological engineering, Zhengzhou University of Light Industry \\ Henan Provincial Collaborative Innovation Center for Food Production and Safety \\ 5\# Dongfeng Road, ZhengZhou city, Henan, China \\ 2014069@zzuli.edu.cn
}

\begin{abstract}
Pyrroloquinoline quinone (PQQ), an important natural product, is biosynthesized by Gluconobacter oxydans. In order to prepare the product in large scale, a rapid and selective chemical complexation extraction (CCE) is proposed to separate and purify PQQ from fermentation broth. In this work, the effect of extraction solvent system, stripping agent, and inorganic ion on the extraction were investigated, respectively. As a result, trioctylamine-octanol system showed the most extraction constants $\left(\log K_{\mathrm{ex}}=5.07\right)$. Ammonia water was the most stripping agent $\left(\log K_{\mathrm{ex}}=4.85\right)$ Several inorganic salts were determined to have negative effect on the extraction, which suggest that inorganic salts should be removed from broth before extraction. Finally, the optimal extraction condition is Trioctylamine-octanol system $(1: 1, \mathrm{v} / \mathrm{v}), 28{ }^{\circ} \mathrm{C}$, and $\mathrm{pH}=6.5$, which leads to more than $90 \%$ of extraction rate. In conclusion, trioctylamine-octanol system and ammonia water showed excellent extraction efficiency, which can be used to prepare PQQ.
\end{abstract}

Keywords: Nature Products; Pyrroloquinoline quinone; Separation; Chemical Complexation Extraction

\section{INTRODUCTION}

Pyrroloquinoline quinone (PQQ, Fig. 1) is an important natural product with many physiological functions, such as antioxidation, promoting growth, and protecting cells [1-2]. Though it shows potential application, plants and animals do not produce PQQ. The source of PQQ in these organisms was shown to be from microorganisms [3]. Several bacteria are able to synthesize PQQ including Acinetobacter calcoaceticus, Pseudomonas fluorescens CHA0, Klebsiella pneumonia, Methylobacterium extorquens AM1, Gluconobacter oxydans, and Methylovorus sp. strain MP688 [4-8]. Their synthesis gene cluster has also been revealed in these bacteria [4-8].<smiles>O=C(O)c1cc(C(=O)O)c2c(n1)C(=O)C(=O)c1cc(C(=O)O)[nH]c1-2</smiles>

Fig. 1 The structure of PQQ
Although PQQ can be biosynthesized in bacteria, the concentration of PQQ in the fermentation broth is very low [9-11]. Furthermore, due to the polar property of PQQ, it cannot easily dissolve in organic solvent, the traditional solvent extraction or solvent sublation is unsuitable to separate PQQ from fermentation liquid. Previously, Zhao reported that ion exchange or reverse column was used to separate and purify PQQ. However, the yield was very low [12]. Therefore, in order to prepare PQQ in large scale, an efficient process of separation for PQQ is very important.

We noted that there are three carboxyl groups in the structure of PQQ, which can be used as functional group for chemical complexation. In this paper, a chemical complexation extraction process has been developed for separation of PQQ. The total extraction rate of the target compound is more than $90 \%$, and the purity of product is $89 \%$. These results suggested that this method can be used to prepare PQQ efficiently.

\section{EXPERIMENTAL}

Reagents and chemicals

Acetonitrile $\left(\mathrm{CH}_{3} \mathrm{CN}\right)$ of HPLC grade was purchased from Sigma-Aldrich (Dorset, UK). Water $\left(\mathrm{H}_{2} \mathrm{O}\right)$ (18.2M $\Omega$ ) was obtained from a Purelab Ultra system from Elga (Bucks, UK). The standard of PQQ was purchased from J\&K. Trioctylamine (AR) was purchased from SigmaAldrich (Dorset, UK). Octanol (AR) was purchased from $\mathrm{J} \& \mathrm{~K}$.

Microorganisms and fermentation conditions

The strain G. oxydans ATCC $621 \mathrm{H}$ was applied to produce PQQ. The fermentation medium was composed of $80 \mathrm{~g} / \mathrm{L}$ sorbitol, $20 \mathrm{~g} / \mathrm{L}$ yeast extract, $5 \mathrm{~g} / \mathrm{L}\left(\mathrm{NH}_{4}\right)_{2} \mathrm{SO}_{4}, 2$ $\mathrm{g} / \mathrm{L} \mathrm{KH}_{2} \mathrm{PO}_{4}$, and $5 \mathrm{~g} / \mathrm{L} \mathrm{MgSO}_{4} \cdot 7 \mathrm{H}_{2} \mathrm{O}$. All media were sterilized by autoclaving at $115^{\circ} \mathrm{C}$ for $15 \mathrm{~min}$. Pre-culture was inoculated with a single cell colony from an agar plate and incubated in shaker with $250 \mathrm{rpm}$ at $28{ }^{\circ} \mathrm{C}$ for $24 \mathrm{~h}$. A $10 \%(\mathrm{v} / \mathrm{v})$ of cells was transferred into the $100 \mathrm{~mL}$ medium in the flask and grown at $28{ }^{\circ} \mathrm{C}$ for $24 \mathrm{~h}$.

Procedure

Fermentation broth and extraction agent $(1: 1, \mathrm{v} / \mathrm{v})$ were put in conical flask, and vibrated for 30 min under $28^{\circ} \mathrm{C}$. A series of mixture liquid, such as trioctylamine mixing with ethyl acetate, petroleum ether, and octanol, was used as 
extraction agents. To preparation PQQ and reused extraction solvent, the extraction solvent and stripping agent $(1: 1, \mathrm{v} / \mathrm{v})$ were put in conical flask, and vibrated for 30 min under $28^{\circ} \mathrm{C}$.

Analysis method of PQQ

According to the literature reported by Yang [13]. The procedure is described as below:

Ten microliters of the PQQ solution was injected into an Agilent UPLC system equipped with waters Acquity UPLC BEH C18, $2.1 \times 100 \mathrm{~mm}, 1.7 \mu \mathrm{m}$ preceded by a Waters Acquity BEH VanGuard C18 guard column packed with $1.7 \mu \mathrm{m}$ packing material. Elution was performed at a flow rate of $200 \mu \mathrm{L} / \mathrm{min}$. The mobile phase was $\mathrm{CH} 3 \mathrm{CN} / \mathrm{H} 2 \mathrm{O}(3: 7, \mathrm{v} / \mathrm{v})$. The total UPLC run time was $10 \mathrm{~min}$. The gradient was increased linearly from $\mathrm{CH}_{3} \mathrm{CN} / \mathrm{H}_{2} \mathrm{O}(3: 7, \mathrm{v} / \mathrm{v})$ to $\mathrm{CH}_{3} \mathrm{CN} / \mathrm{H}_{2} \mathrm{O}(9: 1, \mathrm{v} / \mathrm{v})$ for $6 \mathrm{~min}$, and then the initial conditions were restored and allowed to equilibrate for $4 \mathrm{~min}$.

The qualitative analysis of PQQ was performed using DAD detector on an Agilent Technologies DAD 1290 system (Agilent Technologies Co. Ltd., Palo Alto, CA, USA) and electrospray-ionization tandem mass spectrometer on a Thermo LTQXL $®$ (Thermo Fisher Scientific Inc., Waltham, MA, USA). The ion spray voltage and temperature were optimized for production of the requisite precursor ions in negative- and positive-ion modes. PQQ was analyzed in negative-ion mode. Universal mass spectrometric settings included capillary voltage of $3500 \mathrm{~V}$, cone voltage of $49 \mathrm{~V}$, extractor voltage $9 \mathrm{~V}$, source temperature of $198{ }^{\circ} \mathrm{C}$, desolvation temperature of $300{ }^{\circ} \mathrm{C}$, cone gas flow $110 \mathrm{~L} / \mathrm{h}$, desolvation gas flow $750 \mathrm{~L} / \mathrm{h}$, collision energy of 15 , and dwell times of $150 \mathrm{~ms}$. SRM peak integration sand data analyses were performed using the Analyst ${ }^{\circledR}$ program (Agilent Technologies Co. Ltd., Palo Alto, CA, USA). The collision energy and gas pressure were then optimized for dissociation of deprotonated molecule $[\mathrm{M}-\mathrm{H}]^{-}$into the characteristic product ions.

\section{RESULT AND DISCUSSION}

A series of concentrations of trioctylamine mixing with ethyl acetate, petroleum ether, and octanol were extraction efficiency. The extraction ratios of a series of extraction systems were displayed in the Table-1.Among them, trioctylamine-octanol system showed a high extraction efficiency with $90 \%$ of rate. The effects of volume ratio of Trioctylamine-octanol, tempreture, and $\mathrm{pH}$ were evaluated. The optimal extraction condition is Trioctylamine-octanol system $(1: 1, \mathrm{v} / \mathrm{v}), 28^{\circ} \mathrm{C}$, and $\mathrm{pH}=6.5$.
Table-1 The extraction ratios of a series of extraction systems

\begin{tabular}{cc}
\hline $\begin{array}{c}\text { type of extraction } \\
\text { agent system }\end{array}$ & extraction ratio \\
\hline $\begin{array}{c}\text { ethylacetate- } \\
\text { trioctylamine } \\
\text { n-butyl alcohol- } \\
\text { trioctylamine }\end{array}$ & 53.4 \\
\hline $\begin{array}{c}\text { dichloromethane- } \\
\text { trioctylamine } \\
\text { petroleum ether- } \\
\text { trioctylamine }\end{array}$ & 52.1 \\
octanol--trioctylamine & 56.3 \\
\hline
\end{tabular}

Table-2 Effect of inorganic salts on the extraction of PQQ

\begin{tabular}{lll}
\hline \multicolumn{1}{c}{ type of inorganic salts } & \multicolumn{2}{c}{ extraction ratio } \\
& sorbitol & PQQ \\
\hline no & $6.4 \pm 0.1$ & $91.3 \pm 1$ \\
$\mathrm{NaCl}$ & $0.5 \pm 0.1$ & $28.6 \pm 1$ \\
$\mathrm{MgCl}_{2}$ & $3.8 \pm 0.1$ & $28.5 \pm 1$ \\
$\mathrm{Na}_{2} \mathrm{SO}_{4}$ & $0.4 \pm 0.1$ & $53.4 \pm 1$ \\
$\mathrm{MgSO}_{4}$ & $0.4 \pm 0.1$ & $53.6 \pm 1$ \\
\hline
\end{tabular}

Table-3 Screening of the stripping agent

\begin{tabular}{cc}
\hline type of stripping agent & extraction ratio \\
\hline $\mathrm{NaOH}$ & $90.1 \pm 1$ \\
$\mathrm{Na}_{2} \mathrm{CO}_{3}$ & $90.7 \pm 1$ \\
$\mathrm{NaHCO}_{3}$ & $89.2 \pm 1$ \\
$\mathrm{Na}_{2} \mathrm{HPO}_{4}$ & $68.5 \pm 1$ \\
$\mathrm{NH}_{4} \mathrm{OH}$ & $91.2 \pm 1$ \\
$\mathrm{H}_{2} \mathrm{O}$ & $20.1 \pm 1$ \\
\hline
\end{tabular}

Table-4 Effect of molar ratio (ammonia: succinic acid load in organic phase) on the reextraction

\begin{tabular}{cc}
\hline $\begin{array}{c}\text { molar ratio of } \\
\text { ammonia: PQQ load } \\
\text { in organic phase }\end{array}$ & extraction ratio \\
\hline $4: 5$ & $29.3 \pm 1$ \\
$6: 5$ & $32.5 \pm 1$ \\
$8: 5$ & $43.2 \pm 1$ \\
$10: 5$ & $50.1 \pm 1$ \\
$12: 5$ & $51.2 \pm 1$ \\
$14: 5$ & $51.2 \pm 1$ \\
$16: 5$ & $51.3 \pm 1$ \\
\hline
\end{tabular}

When using chemical complexation extraction for separation of water-soluble compound, the first step, the 
extracted complex was transferred from water phase into organic phase. The preparation of the target compound is the end objective, and then the extraction solvent was reused, which is a key factor for chemical complexation extraction. In the process of chemical complexation extraction, organic carboxylic acid, under free state, was transferred into organic phase. When $\mathrm{pH}$ increasing, the rate of dissociated carboxylic acid goes up. This is so

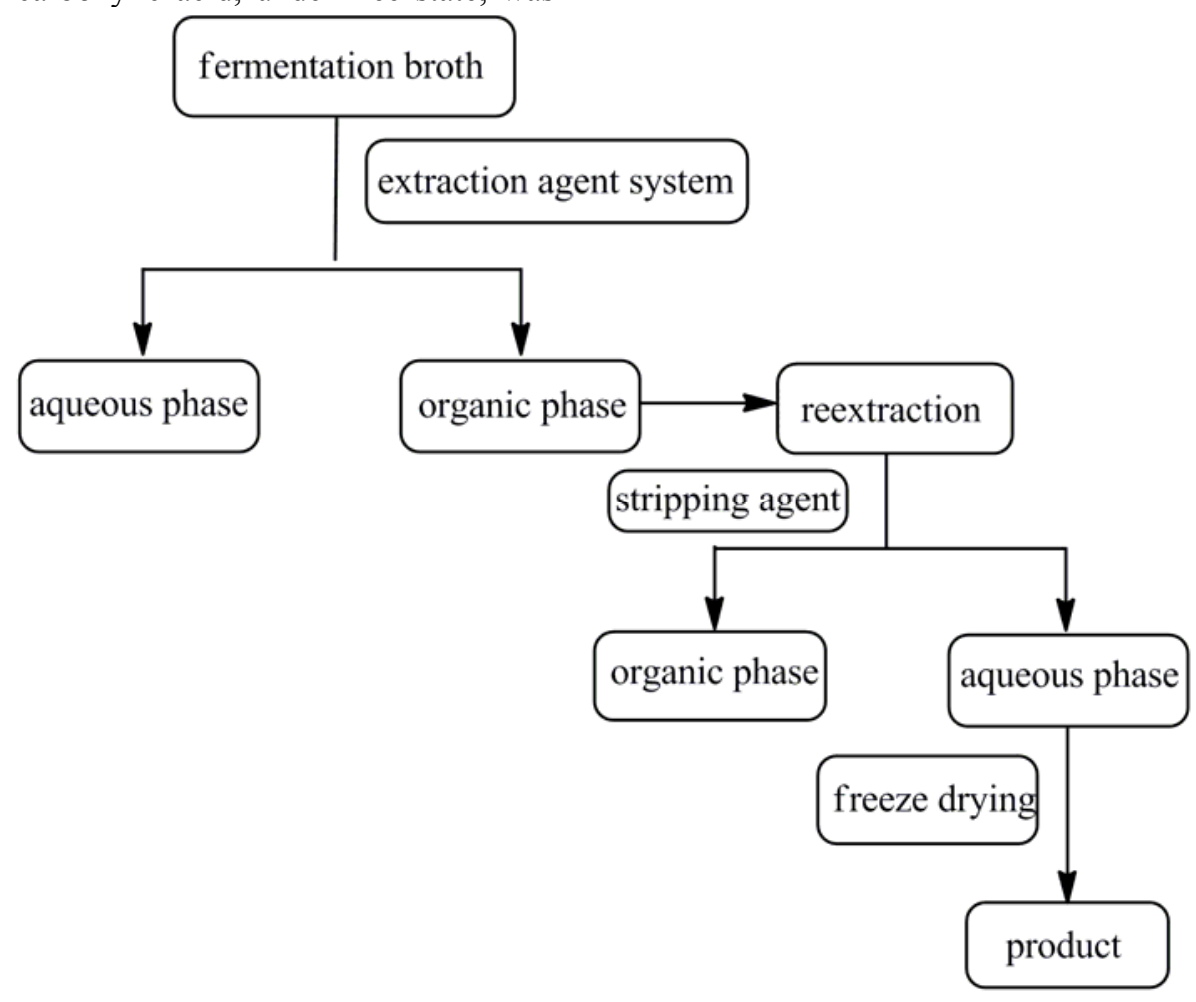

Fig. 2 The technology roadmap of Chemical Complexation Extraction

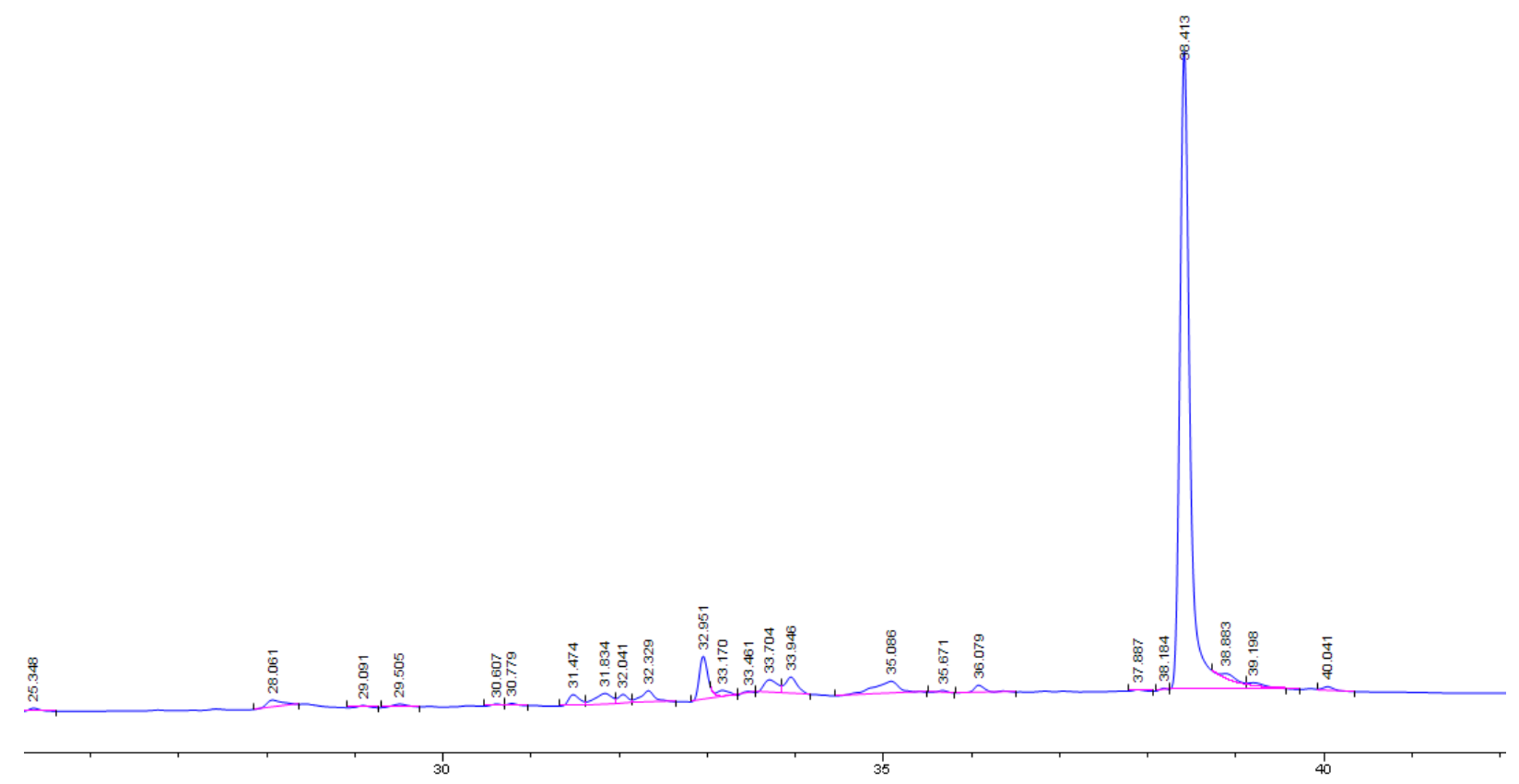

Fig. 3 A profile of the product in HPLC detected by DAD detector at $239 \mathrm{~nm}$

called pH stripping affection. The result of screening of the stripping agent were displayed in Table 3 and 4.Among them, the ammonia water showed an excellent property which leads to a high extraction rate $(>90 \%)$. 
The effects of several inorganic salts on extraction were displayed in the Table-2. The results suggested that the inorganic salts have negative effect on extraction. The anion have the similar effect.

The reason may be the anion could compete with trioctylamine to connect the positive ion. Based on this phenomenon, the inorganic salt should be removed. Therefore, the fermentation broth needs to be pretreated using macroporous resin column, which can remove the inorganic salt.

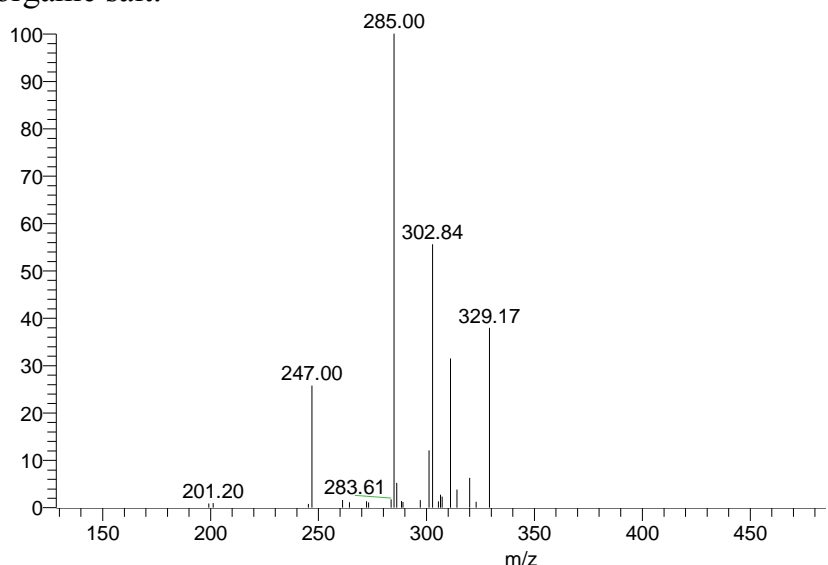

Fig. 4 The characteristic ion fragments for PQQ in the MS

\section{ACKNOWLEDGMENT}

The work was supported by the National Science Foundation of China (21476217).

\section{REFERENCES}

[1] Killgore J, Smidt C, Duich L, Romero-Chapman N, Tinker D, Reiser K, Melko M, Hyde D, Rucker RB (1989) Science, 245:850852.

[2] Steinberg FM, Gershwin ME, Rucker RB (1994) J. Nutr., 124:744753.

[3] Kasahara T, Kato T., (2003) Nature, 422, 832.

[4] Goosen N, Horsman H, Huien R, Putte P., (1989) J. Bacteriol., 171, 447-455.

[5] Schnider U, Keel C, Voisard C, Defage G, Haas D. (1991) Appl Environ Microbiol, 61: 3856-3864.

[6] Toyama H, Chistoserdova L, Lidstrom ME. (1997) Microbiology, 143: 595-602.

[7] Holscher T, and Gorisch H. (2006) J Bacteriology, 188: 7668-7676.

[8] Xiong X, Zhao Y, Ge X, Yuan SJ, Wang J. (2011) Int J Mol Sci., 12: 8913-8923.

[9] Minoru A, Osao A. US: 4994382, 1991, 2, 19.

[10] Urakami T. US: 5344768, 1994, 9, 6.

[11] Wang JH, Zhang WC, Xiong XH, Zhi JJ, et al. CN:102061278B, 2013, 1, 23.

[12] Zhao YF, Wang YS, Wu B, Cheng H, Xu N, Min XR. CN: 1138776C, 2004, 2, 18.

[13] Yang XP, Li PP, Hu XM, Ye JB, Liu Y, Ma K, Mao DB. (2015) Chromatographia, dio: 10.1007/s10337-015-2932-9. 